Delft University of Technology

\title{
Dielectric Response of Corn Leaves to Water Stress
}

van Emmerik, Tim; Steele-Dunne, Susan; Judge, J; van de Giesen, Nick

DOI

10.1109/LGRS.2016.2606662

Publication date

2016

Document Version

Final published version

Published in

IEEE Geoscience and Remote Sensing Letters

\section{Citation (APA)}

van Emmerik, T., Steele-Dunne, S., Judge, J., \& van de Giesen, N. (2016). Dielectric Response of Corn Leaves to Water Stress. IEEE Geoscience and Remote Sensing Letters, 14(1), 8-12.

https://doi.org/10.1109/LGRS.2016.2606662

\section{Important note}

To cite this publication, please use the final published version (if applicable).

Please check the document version above.

\section{Copyright}

Other than for strictly personal use, it is not permitted to download, forward or distribute the text or part of it, without the consent of the author(s) and/or copyright holder(s), unless the work is under an open content license such as Creative Commons.

\section{Takedown policy}

Please contact us and provide details if you believe this document breaches copyrights.

We will remove access to the work immediately and investigate your claim. 


\title{
Dielectric Response of Corn Leaves to Water Stress
}

\author{
Tim van Emmerik, Student Member, IEEE, Susan C. Steele-Dunne, Jasmeet Judge, Senior Member, IEEE, \\ and Nick van de Giesen
}

\begin{abstract}
Radar backscatter from a vegetated surface is sensitive to direct backscatter from the canopy and two-way attenuation of the signal as it travels through the canopy. Both mechanisms are affected by the dielectric properties of the individual elements of the canopy, which are primarily a function of water content. Leaf water content of corn can change considerably during the day and in response to water stress, and model simulations suggested that this significantly affects radar backscatter. Understanding the influence of water stress on leaf dielectric properties will give insight into how the plant water status changes in response to water stress and how radar can be used to detect vegetation water stress. We used a microstrip line resonator to monitor the changes in its resonant frequency at corn leaves, due to variations in dielectric properties. This letter presents the in vivo resonant frequency measurements during field experiments with and without water stress, to understand the dielectric response due to stress. The resonant frequency of the leaf around the main leaf of the stressed plant showed increasing diurnal differences. The dielectric response of the unstressed plant remained stable. This letter shows the clear statistically significant effect of water stress on variations in resonant frequency at individual leaves.
\end{abstract}

Index Terms - Dielectric properties, maize, radar, water stress.

\section{INTRODUCTION}

$\mathbf{T}$ HIS letter is motivated by the potential use of radar for early water stress detection in agricultural canopies. Radar backscatter is sensitive to vegetation because of the direct backscatter from the canopy itself and two-way attenuation of the signal as it travels through the canopy. Both mechanisms are affected by the dielectric constant, architecture, shape, and orientation of all individual scattering elements (leaves, branches, stem, and fruits) within the canopy. In turn, the dielectric properties of these individual scatterers not only are primarily a function of water content but also depend on salinity [1] and temperature [2]. Whether radar backscatter is sensitive to changes in the dielectric properties

Manuscript received February 5, 2016; revised June 16, 2016 and August 9, 2016; accepted September 2, 2016. Date of publication December 8, 2016; date of current version December 26, 2016. This work was supported by the National Aeronautics and Space Administration through the MicroWEX-11 Experiment under Grant NASATHP-NNX09AK29. The work of S. C. Steele-Dunne was supported by The Netherlands Organization for Scientific Research Veni Grant Program under Grant ALW 863.09.015.

T. van Emmerik, S. C. Steele-Dunne, and N. van de Giesen are with the Water Resources Section, Faculty of Civil Engineering and Geosciences, Delft University of Technology, 2628CN Delft, The Netherlands (e-mail: t.h.m.vanemmerik@tudelft.nl).

J. Judge is with the Department of Agricultural and Biological Engineering, University of Florida, Gainesville, FL 32611 USA.

Color versions of one or more of the figures in this paper are available online at http://ieeexplore.ieee.org.

Digital Object Identifier 10.1109/LGRS.2016.2606662 of certain individual elements depends on the radar frequency, polarization, and incidence angle.

Water content in vegetation changes on a diurnal and seasonal scale. Several studies have reported diurnal differences in radar backscatter due to water stress [3], [6]. Recent studies on tree and corn canopies have demonstrated that during periods of low soil moisture availability, the total radar backscatter is mainly sensitive to changes in leaf water content. A modeling study using the Michigan Microwave Canopy Scattering Model (MIMICS [7]) showed that total $C$-band backscatter from a forest canopy is sensitive to the water content of leaves and trunks, especially when at the onset of water stress [8]. Recent research [9] has shown that observed diurnal changes in leaf water content of corn during periods of increased water stress are large enough to have a significant effect on modeled radar backscatter at different frequencies, polarizations, and incidence angles. Both studies highlighted the significant influence of leaf water content on radar backscatter during water stress.

Water stress influences plant water dynamics and might cause early plant death [10]. To prevent excessive water loss and physiological damage, plants regulate transpiration by adjusting the stomatal aperture [11]. Stomatal closure is the result of hydraulic signaling from the roots to the leaves and an increase in the stress hormone abscisic acid (ABA) [12], which is transported through xylem flow and regulates stomatal conductance [13].

It remains unclear how hydrological and plant physiological signatures of water stress affect radar backscatter. A better understanding of how dielectric properties of individual scattering elements, in particular individual leaves, change in response to water stress gives more insights into how radar can be used for water stress detection. Unfortunately, few data sets on in vivo leaf dielectric properties are available [8]. Previous studies have investigated the dielectric properties of vegetation, but most studies focused on tree trunks [14] or used in vivo methods that were not suited for leaves [15]. However, recent field measurements showed a significant dielectric response of tomato leaves to water stress in a greenhouse [16]. In current radar backscatter models and soil moisture algorithms, vegetation is often modeled as a homogeneous layer [17] or as a combination of individual scattering elements [7] with equal moisture content.

This letter uses the in vivo measurements made during two field experiments with a microstrip line resonator, the resonant frequency of which depends on the dielectric constant of the sampled leaf. The first experiment was done on a corn canopy without plant water stress. During the second exper- 


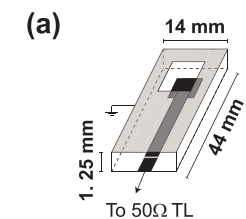

(b)
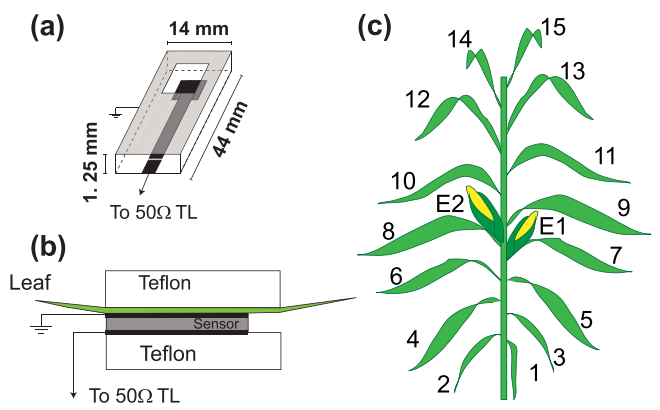

Fig. 1. (a) Microstrip line resonator used for $\Delta f_{r}$ measurements. (b) Illustration of leaf sample placement. (c) Schematic of a corn plant including leaf and ear numbering.
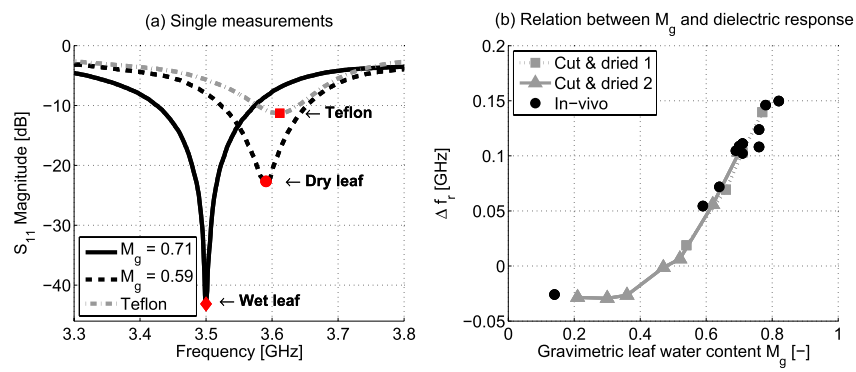

Fig. 2. (a) Measurements of a Teflon block, a wet leaf, and a dry leaf, showing the shift in resonant frequency $f_{r}$ associated with the change in the real part of the dielectric constant of the leaf. (b) Relation between $\Delta f_{r}$ and $M_{g}$, obtained by measuring a leaf before cutting (in vivo) and after (cut and dried) cutting.

iment, water stress was induced by withholding irrigation. The objective of this letter is to understand the dynamics of resonant frequency variation in response to changing the dielectric constant of individual leaves, induced by water stress and plant development.

\section{Methods}

\section{A. Dielectric Response Measurements}

Fig. 1(a) shows the sensor, a microstrip line resonator $(44 \mathrm{~mm} \times 14 \mathrm{~mm} \times 1.25 \mathrm{~mm})$ that senses the leaf through a "sampling window" $(9 \mathrm{~mm} \times 9 \mathrm{~mm})$, cut in the ground plane. Teflon blocks $(1 \mathrm{~cm} \times 4 \mathrm{~cm} \times 3 \mathrm{~cm})$ are placed under the sensor and on top of the leaf [Fig. 1(b)] to ensure that environmental effects are limited to those of a known dielectric constant, and that the leaf is held in place against the sensor with a constant pressure. The sensor was directly attached to Port 1 of a ZVH8 cable and antenna analyzer (ZVH8, 100 kHz-8 GHz, Rohde \& Schwarz, München, Germany) with the K42 vector network analysis and K40 remote control options. For each measurement, the magnitude (dB) of the reflection coefficient $S_{11}$, which depends on the dielectric constant of the sample, was measured at 1201 frequencies over a predefined range. The resonant frequency $f_{r}$ is the frequency at which the magnitude of $S 11$ is at a minimum. An increase in the real part of the dielectric constant of the sample leads to a decrease in the resonant frequency $f_{r}$. Fig. 2 shows the reflection coefficient $S_{11}$ between 3.3 and $3.8 \mathrm{GHz}$ for a typical background measurement of the Telfon blocks and two measurements of single corn leaves with high and low gravimetric water content [2], defined as

$$
M_{g}=\frac{M_{w}-M_{d}}{M_{w}}
$$

where $M_{w}$ and $M_{d}$ are the fresh and dried leaf weights, respectively.

For wet leaves, the dielectric constant is high [18], $f_{r}$ is lower, and the dip in the signal is sharper. For drier leaves, the dielectric constant is lower, leading to a higher $f_{r}$ and a shallower dip in the signal. As the leaf dries out, the difference in $f_{r}$ between the leaf and the Teflon block decreases, due to a decreasing dielectric constant of the leaf. In the subsequent figures and analysis, this difference in $f_{r}$ will be referred to as $\Delta f_{r}(\mathrm{GHz})$. A high value of $\Delta f_{r}$ corresponds to a high value of the dielectric constant of the leaf and a low $\Delta f_{r}$ corresponds to a low dielectric constant. The moisture content of single scatterers (leaves) is expressed here in terms of gravimetric moisture because it is used in the dual-dispersion model [19] as well as models in which dielectric properties of individual scatterers are required (e.g., MIMICS [7]). Fig. 2(b) shows the relationship between $\Delta f_{r}$ and $M_{g}$ for individual leaves from a corn canopy. When leaves are measured as the plant dries down, the decrease in $M_{g}$ clearly results in a decrease in $\Delta f_{r}$. During both field experiments, the resonant frequency was measured at both sides of the middle of the leaf.

\section{B. Unstressed Field Measurements}

Unstressed field measurements were done on a rainfed corn field from July 8 to September 6, 2013 (DOY 189 to 249) near Zeewolde, The Netherlands (N 52.36 ${ }^{\circ}$, E $05.54^{\circ}$ ). Field corn (100-day growing period) was planted on a site of $100 \mathrm{~m} \times 100 \mathrm{~m}$, with a row spacing of $0.7 \mathrm{~m}$, a plant density of 6.6 plants $/ \mathrm{m}$, and a clay soil. This study uses observations of the late vegetative, reproductive, and mature stages of corn (DOY 211 to 220). The plants had a mature average height of $2.20 \mathrm{~m}, 15$ leaves, and 2 ears, located at leaves 7 and 9. No irrigation was applied during the experiment. The precipitation was measured using an HOBO weather station (Onset Computer Co., Bourne, MA, USA). Soil moisture profiles were measured at $0.1,0.2,0.4$, and 0.8 m, using EC-5 soil moisture sensors (Decagon Devices Inc., Pullman, WA, USA) with a measurement interval of $15 \mathrm{~min}$.

The influence of water stress on bulk vegetation water content was determined using destructive vegetation samples every morning and evening. VWC is used here because it is used to describe the moisture content of the canopy in the water cloud model [17]. To determine the total, leaf, and stem VWC, one corn plant was cut, weighed with leaves, stems, and ear separated, dried in a $70{ }^{\circ} \mathrm{C}$ oven for 48 (leaves) or $120 \mathrm{~h}$ (stems and ears), and weighed again. The VWC values of leaves and stems were determined from the fresh and dry masses $\left(M_{w}\right.$ and $\left.M_{d}\right)$, using

$$
V W C=\eta\left[\left(M_{w, l}-M_{d, l}\right)+\left(M_{w, s}-M_{d, s}\right)\right]
$$

where $\eta$ is the number of plants $/ \mathrm{m}^{2}$ and the superscripts $l$ and $s$ indicate leaves and stems, respectively. Resonant frequency measurements were made between 3.1 and $4.1 \mathrm{GHz}$ at $6 \mathrm{~A} . \mathrm{M}$. and 6 P.M., immediately preceding the destructive vegetation sampling. Between DOY 211 and 220, leaves 1 to 12 were measured and measurements were taken every day. Trends were calculated for the total data series, A.M. measurement, 
TABLE I

TRENDS IN $\Delta f_{r}$ FOR THE STRESSED AND UNSTRESSED CANOPIES, Calculated Using SPearman's Rank CoefFicient. Positive Trends Are Indicated With (+), Negative Trends With (-), and No Significant Trends With (n.t.). Total Means All Data Points of the Time Series and A.M. AND P.M. ARe the Morning and Evening Values Only. THE DiURNAL DiFFERENCE REFERS TO DIFFERENCES BETWEEN A.M. AND P.M.

\begin{tabular}{|c|c|c|c|c|}
\hline Leaf No. & Total & A.M. & P.M. & Diurnal difference \\
\hline \multicolumn{5}{|c|}{ Flevoland (unstressed) } \\
\hline $\mathbf{1 1}$ & n.t. & n.t. & n.t. & n.t. \\
$\mathbf{9}$ & +0.99 & +0.99 & n.t. & n.t. \\
$\mathbf{7}$ & n.t. & n.t. & +0.92 & n.t. \\
\hline \multicolumn{5}{|c|}{ Florida (stressed) } \\
\hline $\mathbf{1 2}$ & n.t. & n.t. & n.t. & n.t. \\
$\mathbf{1 0}$ & +0.99 & +0.99 & +0.95 & n.t. \\
$\mathbf{8}$ & n.t. & n.t. & -0.96 & +0.94 \\
\hline
\end{tabular}

P.M. measurements, and the diurnal difference (P.M.-A.M.), using Spearman's correlation coefficient, expressed as confidence boundaries. Only values higher than 0.9 were considered statistically significant trends.

Note from Fig. 2(a) that $\Delta f_{r}$ is related to the gravimetric moisture content of an individual leaf and not to the bulk moisture content of the canopy. Unfortunately, $M_{g}$ data are not available for the field trial described here.

\section{Stressed Field Measurements}

Fieldwork under stressed conditions was conducted near Citra, FL (N 29.41 ${ }^{\circ}, \mathrm{W} 82.18^{\circ}$ ), as part of the MicroWEX-11 experiment [20] from April 25 to December 9, 2012 (DOY 115 to 343). Sweet corn (78-day growing period) was planted on a site with a sandy soil of $183 \mathrm{~m} \times 183 \mathrm{~m}$, a $1-\mathrm{m}$ row spacing, and a plant density of 5 plants $/ \mathrm{m}$. This study used observations during the late vegetative and reproductive periods (DOY 281 to 292). Water stress was induced by withholding irrigation at the vegetation sampling location. The corn plants had an average mature height of $1.8 \mathrm{~m}$, 12 leaves and 1 ear, located at leaf 8. Precipitation data were obtained from the Florida Automated Weather Network. The soil moisture profile was measured at six depths of 0.02, 0.04, $0.16,0.32,0.64$, and $1.2 \mathrm{~m}$ at the site using Campbell Scientific CS616 time-domain water content reflectometers (Campbell Scientific, Inc., Logan, UT, USA). From DOY 281 to 292, daily destructive samples were taken at 6 A.M. and 6 P.M. To determine the total leaf and stem water content, two corn plants were cut, weighed with leaves and stems separated, dried in a $70{ }^{\circ} \mathrm{C}$ oven for 48 and $120 \mathrm{~h}$, respectively, and weighed again. Resonant frequency measurements were made between 2.1 and $4.1 \mathrm{GHz}$ from DOY 281 to 292, at 6 A.M. and 6 P.M., immediately preceding the destructive vegetation sampling. All measurements were performed on the same corn plant throughout the experiment.

\section{RESUlTS}

\section{A. Unstressed Field Measurements}

Fig. 3(a) shows the precipitation and root zone soil moisture in the unstressed canopy. Although only few rainfall events occurred during the measured period, the root zone soil moisture remained high $\left(0.4-0.45 \mathrm{~m}^{3} / \mathrm{m}^{-3}\right)$. Fig. 3(b) and (c) presents the total stem and leaf water content. The stem water content decreased gradually during the reproductive phase. The leaf water content is constant after DOY 211. Fig. 4(a)-(c) presents the differences in resonant frequency $\left(\Delta f_{r}\right)$ of leaves 7, 9, and 11. $\Delta f_{r}$ is stable for all three leaves and only for leaf 7 diurnal variations were observed. From DOY 211 to 214, the 6 A.M. values were higher than the 6 P.M. values. Table I presents the trends in $\Delta f_{r}$. Leaf 7 shows an increasing trend in the P.M. values and leaf 9 shows positive trends in the total and in the A.M. data. During measurement period, the plant was still in the vegetative stages, which led to an increased leaf water content (and hence dielectric constant) in the leaves around the ears (leaves 7 and 9). The laboratory measurements found the instrument error to be $0.001 \mathrm{GHz}$ and the reproducibility error, defined as the error when moving and reapplying the sensor, to be $0.009 \mathrm{GHz}$. Both errors were significantly smaller than the observed diurnal differences of $\Delta f_{r}$ at leaf $7(0.04 \mathrm{GHz})$ and the total change of $\Delta f_{r}$ at leaves 7 and $9(0.05 \mathrm{GHz})$.

\section{B. Stressed Field Measurements}

During the measurement period in the stressed canopy, no precipitation events occurred [Fig. 5(a)]. Root zone soil moisture remained low during this period $\left(0.1 \mathrm{~m}^{3} / \mathrm{m}^{-3}\right)$. Note that although irrigation was switched OFF at the vegetation sampling location, it continued at the soil moisture probes. These events are indicated as $I_{x}$, meaning that soil moisture at the vegetation sampling site is overestimated. Fig. 5(b) and (c) shows the total stem and leaf water content, respectively. After the onset of water stress on DOY 280, stem water content and 6 A.M. and 6 P.M. leaf water content decreased. The diurnal differences in leaf water content are the highest between DOY 281 and 284, just after the onset of water stress. Fig. 6(a)-(c) shows the difference in resonant frequency $\Delta f_{r}$ time series at leaves 8, 10, and 12. Leaves 10 and 12 show a very stable signal from DOY 281 to 292. There are small diurnal differences in $\Delta f_{r}$, similar in magnitude to the measurements in the unstressed canopy. A positive trend was observed in the A.M. and P.M. values of leaf 10 (Table I). Leaf 8 shows a clear decreasing trend in the 6 P.M. values and an increasing trend in the diurnal variation. The diurnal variation of leaf 8 (increasing from 0.048 to $1.675 \mathrm{GHz}$ ) is considerably higher than in other leaves (about $0.030 \mathrm{GHz}$ ).

\section{DISCUSSION}

Leaf water content of the stressed corn canopy decreased significantly, in contrast to the unstressed canopy, where leaf water content remained stable during the measurement period. Water stress also had an effect on the diurnal differences in leaf water content, which increased just after the onset of water stress. The resonant frequency measurements revealed a dynamic vertical profile of the dielectric response in both the unstressed and the stressed canopy. During normal conditions, the slowly increasing resonant frequency at leaves 7 and 9 are a sign of the growing canopy, suggesting the increasing 


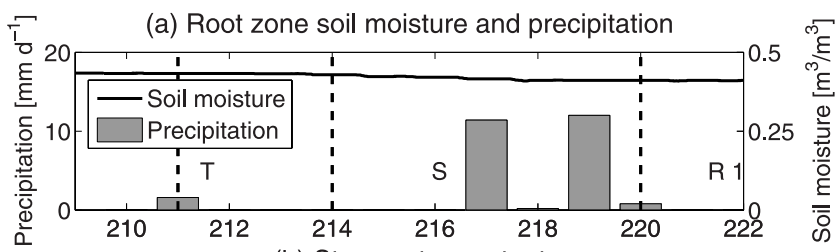

(b) Stem water content

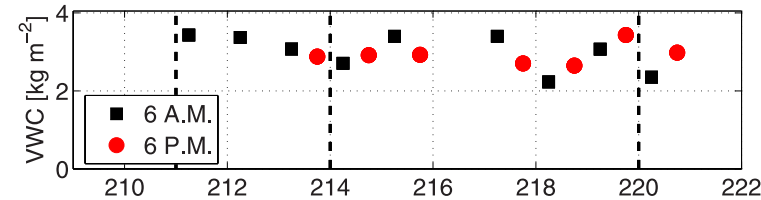

(c) Leaf water content

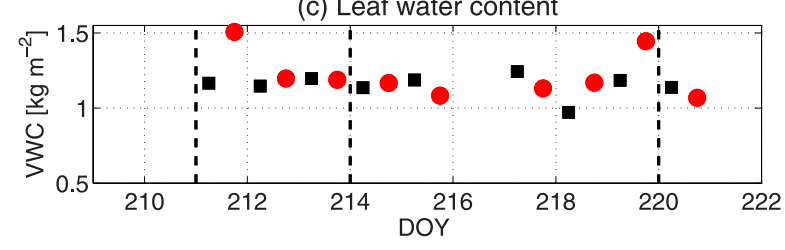

Fig. 3. Unstressed canopy. (a) Precipitation and root zone soil moisture. (b) Stem water content. (c) Leaf water content. The stages are included in (a), $\mathrm{T}=$ tasseling, $\mathrm{S}=$ silking, and $\mathrm{R} 1=$ reproductive stage.

(a) $\Delta f_{r}$, unstressed, Leaf 11

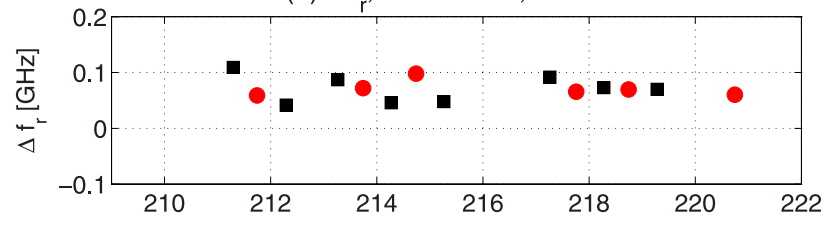

(b) $\Delta \mathrm{f}_{\mathrm{r}}$, unstressed, Leaf 9

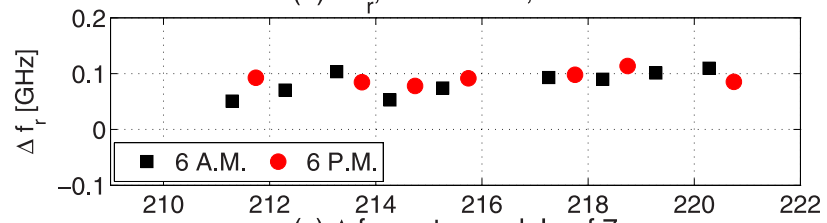

(c) $\Delta \mathrm{f}_{\mathrm{r}}$, unstressed, Leaf 7

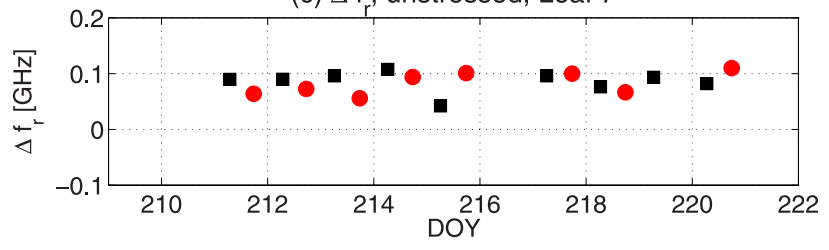

Fig. 4. Unstressed canopy. Dielectric response $\Delta f_{r}$ on leaves (a) 11, (b) 9 , and (c) 7 .

leaf water content and dielectric constant of these leaves. The leaves of the stressed canopy also demonstrated dynamic behavior, depending on the height of the leaf. The contrasting trends of the resonant frequencies at leaves 8 and 10 suggest a change in the vertical water distribution between leaves. However, the effect of water stress was mostly visible through the increasing diurnal variation in resonant frequency of leaf 8 . Such diurnal variations occur only during times of severe water stress, as isohydric species are unable to prevent water loss for all leaves. Individual leaves respond differently to an increase in stress hormone ABA, which is not reflected in the bulk leaf water content. The older lower leaves are less responsive to ABA [21] and are therefore likely to have caused the large diurnal differences in total leaf water content. Also, the highest photosynthetic rates occur at the leaf close

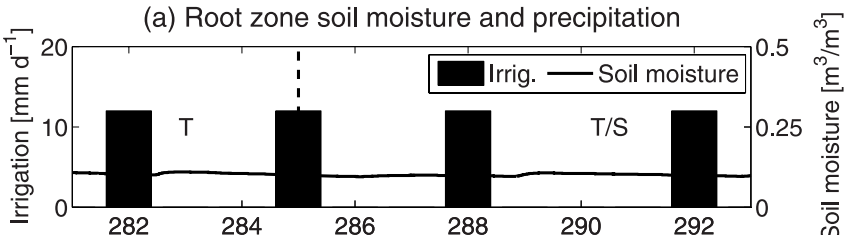

(b) Stem water content
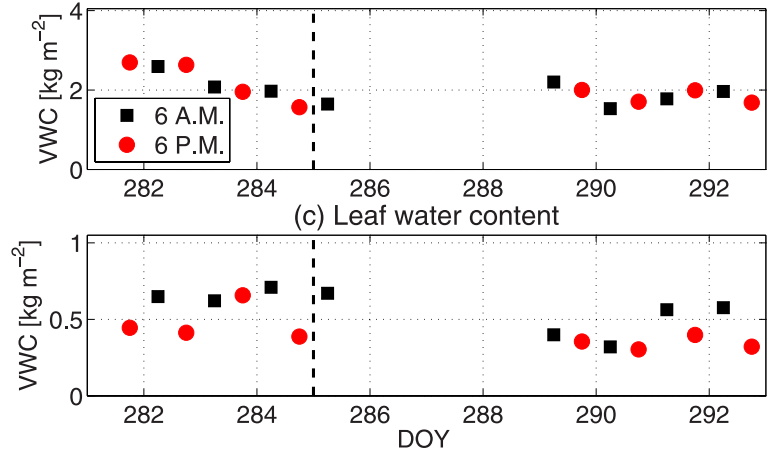

Fig. 5. Stressed canopy. (a) Precipitation (not between DOY 281 and 293), irrigation at the soil moisture measurement site only, and root zone soil moisture. (b) Stem water content. (c) Leaf water content. The stages are included in (a), $\mathrm{T}=$ tasseling, and $\mathrm{T} / \mathrm{S}=$ start silking.

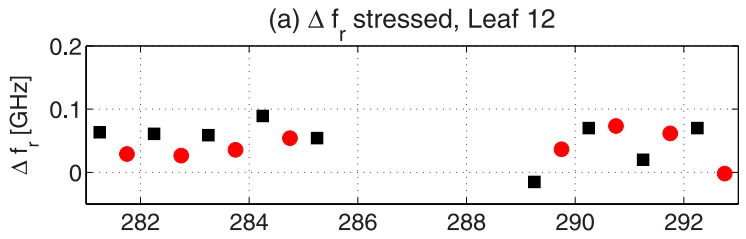

(b) $\Delta \mathrm{f}_{\mathrm{r}}$ stressed, Leaf 10

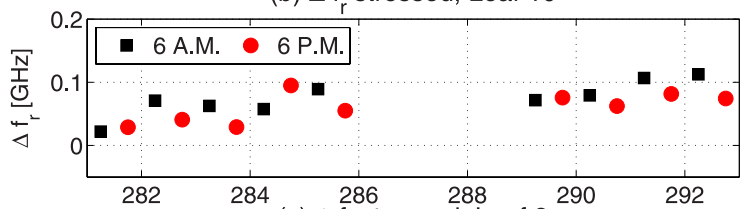

(c) $\Delta f_{r}$ stressed, Leaf 8

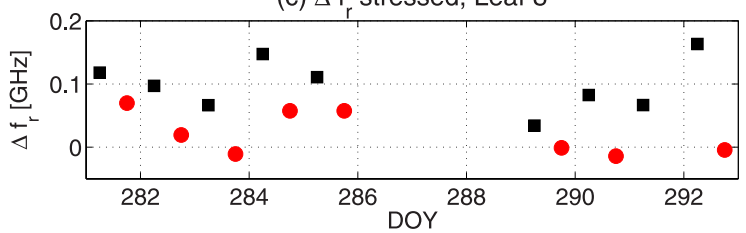

Fig. 6. Stressed canopy. Dielectric response $\Delta f_{r}$ on leaves (a) 12 , (b) 10 , and (c) 8 .

to the main ear and stomatal control at this leaf is limited to maximize $\mathrm{CO}_{2}$ uptake. The leaf at the ear (leaf 8) provides carbon for the development of the ear. If the stomata would close too soon, carbon assimilation will decrease and the development of the ear would be jeopardized [22]. Therefore, it is important for corn to keep the leaf at the ear transpiring water, even when this leads to higher water losses in the leaf. The upper leaves, smaller and less important for survival, showed no trend in diurnal variation. Therefore, results suggest that the decline in total leaf water content is primarily due to changes in the larger leaves close to the ear (e.g., leaf 8). Our observations are consistent with the previously observed response of corn to water stress, which have shown a vertical 
profile in plant physiological variables, such as photosynthetic rate, transpiration rate, and stomatal conductance [22]- [25]. The coupling between plant physiological effects of water stress and the dielectric properties of individual leaves is important to assess the potential of water stress detection using radar. Water stress does not cause a homogeneous reaction of the canopy as a whole. In radar backscatter models or soil moisture retrieval algorithms, vegetation is often modeled as a single layer (water cloud) or as a layer of individual scatterers. In both cases, the vertical profile of leaf water content and thus leaf dielectric constant are not taken into account. We show that when a change in total vegetation was observed, leaves do not necessarily react similarly. Whether radar backscatter is sensitive to a changing vertical profile of leaf dielectric properties depends on the used radar frequency, polarization, and incidence angle.

\section{CONCLUSION}

This letter shows that after the onset of water stress, the dielectric response of the leaves around the ear is mainly affected. The results of this first field application are promising, as these results demonstrate the dynamic behavior of leaf dielectric constant. The leaf dielectric properties change with time and their response to plant growth and water stress depends on the height and age of the leaf.

The in vivo resonant frequency measurements suggest that leaf dielectric properties are dynamic in time and space. The variation in leaf dielectric properties, in response to plant growth or water stress, depends on the height of the leaf. The resonant frequency measurements on the stressed canopy clearly showed an effect of water stress on the leaf dielectric response. The leaf at the ear showed an increase in diurnal differences in $\Delta f_{r}$, as well as a negative trend in 6 P.M. values. This highlights the importance of understanding the effect of water stress on the dielectric properties of individual elements within the canopy.

Current efforts are focusing on extracting the real and imaginary parts of the dielectric constant from the full frequency sweeps. Radar backscatter sensitivity studies are required to investigate what radar frequencies, polarizations, and incidence angles are most sensitive to these changes in the canopy. Additional measurement campaigns are required to study the changes in dielectric properties due to water stress of other agricultural canopies or forests.

\section{REFERENCES}

[1] S. O. Nelson, "Dielectric properties of agricultural productsmeasurements and applications," IEEE Trans. Elect. Insul., vol. 26, no. 5, pp. 845-869, Oct. 1991.

[2] F. T. Ulaby and R. P. Jedlicka, "Microwave dielectric properties of plant materials," IEEE Trans. Geosci. Remote Sens., vol. GE-22, no. 4, pp. 406-415, Jul. 1984.

[3] S. Frolking et al., "Tropical forest backscatter anomaly evident in SeaWinds scatterometer morning overpass data during 2005 drought in Amazonia," Remote Sens. Environ., vol. 115, no. 3, pp. 897-907, Mar. 2011.
[4] J. Friesen et al., "Spatial and seasonal patterns of diurnal differences in ERS scatterometer soil moisture data in the Volta Basin, West Africa," IAHS Red Book Ser., vol. 316, pp. 47-55, Jul. 2007.

[5] J. Friesen, "Regional vegetation water effects on satellite soil moisture estimations for West Africa," Ecol. Develop. Ser, no. 63, 2008.

[6] J. Friesen, S. C. Steele-Dunne, and N. van de Giesen, "Diurnal differences in global ERS scatterometer backscatter observations of the land surface," IEEE Trans. Geosci. Remote Sens., vol. 50, no. 7, pp. 2595-2602, Jul. 2012.

[7] F. T. Ulaby, K. Sarabandi, K. McDonald, M. Whitt, and M. C. Dobson, "Michigan microwave canopy scattering model," Int. J. Remote Sens., vol. 11, no. 7, pp. 1223-1253, 1990.

[8] S. C. Steele-Dunne, J. Friesen, and N. V. D. Giesen, "Using diurnal variation in backscatter to detect vegetation water stress," IEEE Trans. Geosci. Remote Sens., vol. 50, no. 7, pp. 2618-2629, Jul. 2012.

[9] T. van Emmerik, S. C. Steele-Dunne, J. Judge, and N. van de Giesen, "Impact of diurnal variation in vegetation water content on radar backscatter from maize during water stress," IEEE Trans. Geosci. Remote Sens., vol. 53, no. 7, pp. 3855-3869, Jul. 2015.

[10] H. G. Jones and F. Tardieu, "Modelling water relations of horticultural crops: A review," Sci. Horticulturae, vol. 74, nos. 1-2, pp. 21-46, Apr. 1998.

[11] P. Jarvis, "The interpretation of the variations in leaf water potential and stomatal conductance found in canopies in the field," Philos. Trans. Royal Soc. London B, Biol. Sci., vol. 273, no. 927, pp. 593-610, 1976

[12] S. A. M. McAdam and T. J. Brodribb, "Separating active and passive influences on stomatal control of transpiration," Plant Physiol., vol. 164, pp. 1578-1586, Apr. 2014.

[13] F. Tardieu, J. Zhang, and W. J. Davies, "What information is conveyed by an ABA signal from maize roots in drying field soil?" Plant, Cell Environ., vol. 15, no. 2, pp. 185-191, Feb. 1992.

[14] K. C. McDonald, R. Zimmermann, and J. S. Kimball, "Diurnal and spatial variation of xylem dielectric constant in Norway Spruce (Picea abies [L.] Karst.) as related to microclimate, xylem sap flow, and xylem chemistry," IEEE Trans. Geosci. Remote Sens., vol. 40, no. 9, pp. 2063-2082, Sep. 2002.

[15] J. Way et al., "Diurnal change in trees as observed by optical and microwave sensors: The EOS synergism study," IEEE Trans. Geosci. Remote Sens., vol. 29, no. 6, pp. 807-821, Nov. 1991.

[16] T. van Emmerik, S. Steele-Dunne, J. Judge, N. van de Giesen, "A comparison between leaf dielectric properties of stressed and unstressed tomato plants," in Proc. 35th Annu. IGARSS, vol. 1. Milan, Italy, Jul. 2015, pp. 275-278.

[17] E. P. W. Attema and F. T. Ulaby, "Vegetation modeled as a water cloud," Radio Sci., vol. 13, no. 2, pp. 357-364, Mar./Apr. 1978.

[18] M. El-Rayes and F. Ulaby, "Microwave dielectric spectrum of vegetation-Part I: Experimental observations," IEEE Trans. Geosci. Remote Sens., vol. 25, no. 5, pp. 541-549, Sep. 1987.

[19] F. T. Ulaby and M. A. El-Rayes, "Microwave dielectric spectrum of vegetation-Part II: Dual-dispersion model," IEEE Trans. Geosci. Remote Sens., vol. GE-25, no. 5, pp. 550-557, Sep. 1987.

[20] T. Bongiovanni et al., "Field observations during the eleventh microwave water and energy balance experiment (MicroWEX-11): From April 25, 2012, through December 6, 2012," Center Remote Sens., Univ. Florida, Gainesville, FL, USA, Tech. Rep. AE514, 2015. [Online]. Available: http://edis.ifas.ufl.edu/pdffiles/ae/ae51400.pdf

[21] J. Zhang and W. J. Davies, "Does ABA in the xylem control the rate of leaf growth in soil-dried maize and sunflower plants?" J. Experim. Botany, vol. 41, no. 9, pp. 1125-1132, 1990.

[22] L. M. Dwyer and D. W. Stewart, "Effect of leaf age and position on net photosynthetic rates in maize (Zea mays L.)," Agricult. Forest Meteorol., vol. 37, no. 1, pp. 29-46, May 1986.

[23] N. C. Turner, "Stomatal behavior and water status of maize, sorghum, and tobacco under field conditions," Plant Physiol., vol. 53, no. 3, pp. 360-365, Mar. 1974.

[24] E. Acevedo, E. Fereres, T. C. Hsiao, and D. W. Henderson, "Diurnal growth trends, water potential, and osmotic adjustment of maize and sorghum leaves in the field," Plant Physiol., vol. 64, no. 3, pp. 476-480, Sep. 1979.

[25] P. Rochette, E. Pattey, R. L. Desjardins, L. M. Dwyer, D. W. Stewart, and P. A. Dubé, "Estimation of maize (Zea mays L.) canopy conductance by scaling up leaf stomatal conductance," Agricult. Forest Meteorol., vol. 54, nos. 2-4, pp. 241-261, Apr. 1991. 